\title{
Comunicação
}

[Communication]

\section{Mielograma de ratas com disfunção tireoidiana}

\author{
[Bone marrow examination in rats with thyroid dysfunction]
}

\author{
R.D. Castro, J.F. Silva, N.M. Ocarino, J.N. Boeloni, P.P. Nunes, G.R. Silva, M.M. Melo, \\ P.R.O. Paes, R. Serakides* \\ Escola de Veterinária UFMG \\ Caixa Postal 567 \\ 30123-970 - Belo Horizonte, MG
}

Os hormônios tireoidianos, tri-iodotironina (T3) e tiroxina (T4), são requeridos para o funcionamento adequado de diversos sistemas orgânicos, dentre eles o sistema hematopoético, onde estimulam a eritropoese e a resposta imune (Gomes et al., 2008). As células-tronco pluripotentes da medula óssea, sob ação de fatores de crescimento, interleucinas $\mathrm{e}$ hormônios, sofrem diferenciação e maturação, e evidências apontam os hormônios tireoidianos como agentes capazes de interferir no processo de desenvolvimento das linhagens celulares da medula óssea (Brent, 1994).

T3 e T4 influenciam direta ou indiretamente a hematopoese (Brent, 1994). Embora a ocorrência de anemia no hipotireoidismo seja bem conhecida (Gomes et al., 2004), sua gênese ainda é controversa. Existem afirmativas que justificam a anemia como uma resposta ao decréscimo da demanda de oxigênio, e outras como uma resposta a processos mais complexos, como a indiferenciação eritroide (Dinnen et al., 1994), a redução da ação do ácido retinoico e a interferência na síntese de eritropoetina (Schroeder et al., 1992).

No hipertireoidismo não há alterações do hematócrito, da hemoglobina e do número de eritrócitos em ratos (Carneiro et al., 2000). Entretanto, já foi relatado que $34 \%$ dos pacientes humanos com hipertireoidismo apresentam anemia (Hambsch et al., 1989).

Recebido em 13 de março de 2011

Aceito em 13 de julho de 2011

*Autor para correspondência (corresponding author)

E-mail: serakidesufmg@gmail.com
Não somente a série eritroide das células hematopoéticas sofre influência da tireoide. Os hormônios tireoidianos parecem estimular a linfopoese B primária (Montecino-Rodriguez et al., 1997) e são requeridos para a produção normal das células $\mathrm{B}$ na medula óssea, pelo controle da proliferação das células pró-B (Foster et al., 1999).

Embora existam evidências, por meio do hemograma e de ensaios de proliferação e diferenciação celular, de que os hormônios tireoidianos atuam como moduladores da atividade normal da medula óssea, ainda não há estudos que avaliaram de forma quantitativa e detalhada as células da linhagem mieloide, linfoide e eritroide da medula óssea de indivíduos com disfunções tireoidianas. Assim, o objetivo deste estudo foi caracterizar as alterações do mielograma de ratas com hipo e hipertireoidismo induzidos experimentalmente.

Foram utilizadas 15 ratas Wistar adultas com dois meses de idade. As ratas foram alojadas em caixas plásticas (cinco ratas/ caixa) e receberam ração comercial $(1,4 \%$ de cálcio, $0,6 \%$ de fósforo, $22 \%$ de proteína e micronutrientes em concentrações recomendadas) e água ad libitum. Os animais foram mantidos em regime de 12 horas de luz e 12 horas de escuro.

Após um período de adaptação de sete dias, as ratas foram distribuídas em três grupos: hipotireoideo $(n=5)$, hipertireoideo $(n=5)$ e 
controle $(n=5)$. O hipotireoidismo foi induzido pela administração de 6-propyl-2-thiouracil (Sigma, St Louis, MO, USA) - 1mg/animal diluído em $5 \mathrm{~mL}$ de água destilada. Para a indução do hipertireoidismo, foi administrada Ltiroxina (Sigma, St Louis, MO, USA) $50 \mu \mathrm{g} / \mathrm{animal}$ - diluída em $5 \mathrm{~mL}$ de água destilada. $\mathrm{O}$ grupo-controle (eutireoideo) recebeu $5 \mathrm{~mL}$ de água destilada como placebo. Todos os grupos receberam o tratamento por sonda orogástrica. Três meses após o início dos tratamentos, procedeu-se à eutanásia dos animais por punção cardíaca, após anestesia. O plasma sanguíneo foi colhido para dosagem de T4 livre pela técnica da quimioluminescência (Access Immunoassay System, Sanofi Diagnostics Pasteur Inc., Chaska, MN, USA) em sistema totalmente automático, a fim de confirmar a indução dos estados hipotireoideo e hipertireoideo. Os coeficientes de variação intra- ensaio e interensaio foram de $4 \%$ e $7 \%$, respectivamente.

Durante a necropsia, retiraram-se os fêmures direito e esquerdo de cada animal. As epífises craniais destes ossos foram seccionadas em bisel, seguido de inserção de uma agulha hipodérmica embebida em EDTA a 3\% no canal medular. A medula óssea foi aspirada para a confecção dos esfregaços, que foram corados pelo método do panótico rápido. Sob objetiva de imersão, foi determinada a porcentagem de rubroblasto, prórubrócito, rubrócito, metarubrócito, mieloblasto, promielócito, metamielócito, mielócito, bastonete, eosinófilos, basófilo, neutrófilo, linfócito, plasmócito e monócito em um total de 500 células. Para a identificação das células, foram considerados os aspectos referentes ao diâmetro celular, bem como a morfologia nuclear e a citoplasmática (Fig. 1).

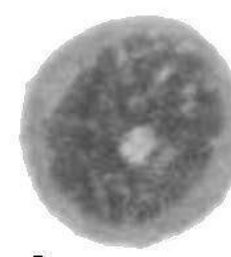

A

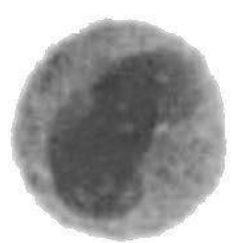

$\mathbf{F}$

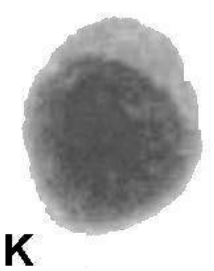

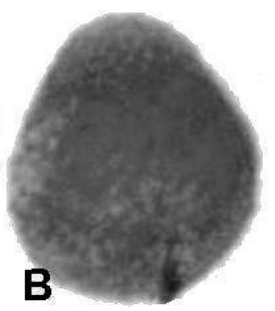

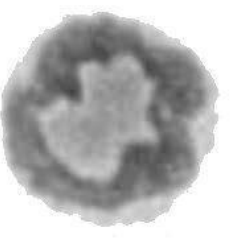

G

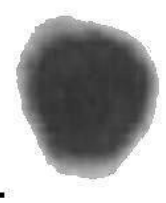

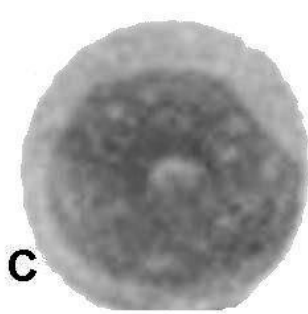

D
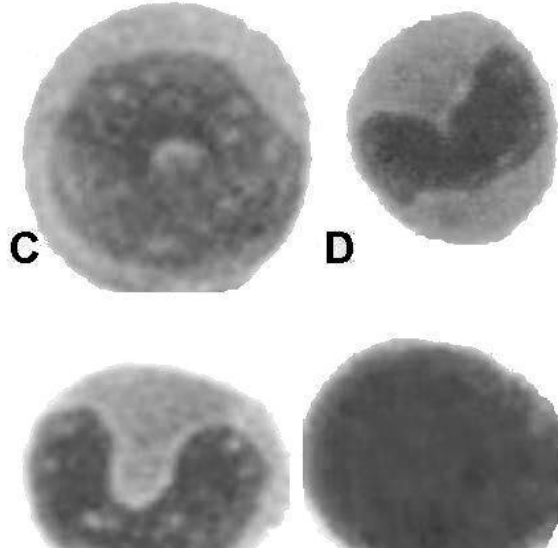

H
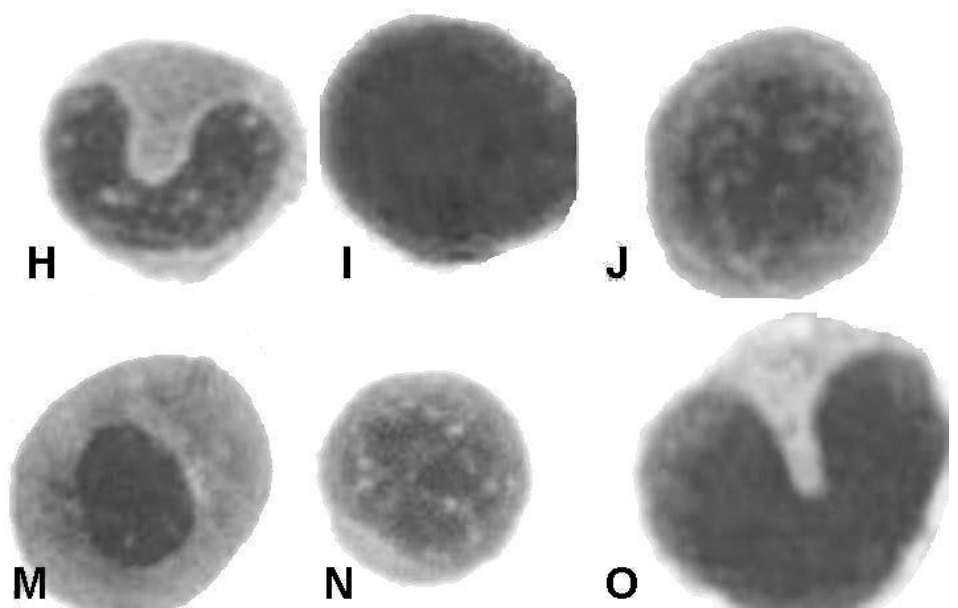

E

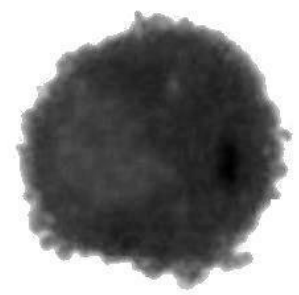

N

Figura 1. Esfregaço da medula óssea de ratas com as linhagens celulares. Panótico, 250×. A) mieloblasto, B) promielócito, C) mielócito, D) metamielócito, E) basófilo, F) eosinófilo, G) neutrófilo, H) bastonete, I) rubroblasto, J) pró-rubrócito, K) rubrócito, L) metarubrócito, M) plasmócito, N) linfócito, O) monócito.

Foi calculado o percentual de cada grupo celular e de células eritroides e mieloides maduras. A relação mieloide:eritroide foi calculada dividindo-se o total das células mieloides pelo total das células eritroides. Os dados foram submetidos à análise de variância com comparação das médias pelo teste SNK. Diferenças foram consideradas significativas 
se $\mathrm{P}<0,05$. Todos os procedimentos foram aprovados pelo Comitê de Ética em Experimentação Animal da UFMG.

A indução do hipo e do hipertireoidismo foi comprovada pelas concentrações plasmáticas de T4 livre e pela sintomatologia. As ratas tratadas com propiltiouracil apresentaram níveis de T4 livre significativamente menores do que as do grupocontrole (Tab. 1) e sinais clínicos caracterizados por letargia e alopecia. No entanto, as ratas tratadas com tiroxina apresentaram níveis plasmáticos de T4 livre significativamente maiores do que as do grupo-controle e sinais clínicos caracterizados por agressividade, exoftalmia, polifagia e polidpsia.

A medula óssea das ratas com hipotireoidismo apresentou-se hipocelularizada, com redução das linhagens eritroide e mieloide e com grande quantidade de adipócitos caracterizando a hipoplasia medular.

A relação mieloide:eritroide foi significativamente maior em relação à do grupo-controle, tanto no grupo hipotireoideo quanto no hipertireoideo (Tab. 2). Este valor é usado para caracterizar anormalidades no processo de maturação celular bem como da hematopoese (Patt, 1957), sendo que Bauer et al. (1998) verificaram que a ativação do receptor do hormônio tireoidiano influencia na proliferação e diferenciação da linhagem eritroide. Esta alta relação mieloide:eritroide nos grupos tratados deveu-se ao aumento da população de células da linhagem mieloide e à redução da linhagem eritroide.

Tabela 1. Média e desvio-padrão da concentração plasmática de T4 livre nos grupos controle, hipotireoideo e hipertireoideo

\begin{tabular}{lccr}
\hline \multirow{2}{*}{ Variável } & \multicolumn{3}{c}{ Grupo } \\
\cline { 2 - 4 } & Controle & Hipotireoideo & Hipertireoideo \\
\hline T4 livre (ng) & $1,699 \pm 0,423 \mathrm{~B}$ & $0,029 \pm 0,047 \mathrm{C}$ & $4,179 \pm 0,927 \mathrm{~A}$ \\
\hline Médias seguidas por letras distintas na linha indicam valores diferentes pelo teste SNK $(\mathrm{P}<0,05)$.
\end{tabular}

Tabela 2. Média e desvio-padrão da porcentagem de células da medula óssea e proporção de células das linhagens mieloide e eritroide nos grupos controle, hipotireoideo e hipertireoideo

\begin{tabular}{lccc}
\hline \multicolumn{1}{c}{ Porcentagem de } & \multicolumn{3}{c}{ Grupo } \\
\cline { 2 - 4 } \multicolumn{1}{c}{ células } & Controle & Hipotireoideo & Hipertireoideo \\
\hline Mieloblasto & $3,96 \pm 4,1 \mathrm{~A}$ & $2,74 \pm 2,11 \mathrm{~A}$ & $5,17 \pm 4,26 \mathrm{~A}$ \\
Promielócito & $1,97 \pm 1,04 \mathrm{~A}$ & $1,19 \pm 0,69 \mathrm{~A}$ & $1,95 \pm 1,68 \mathrm{~A}$ \\
Mielócito & $9,59 \pm 5,45 \mathrm{~B}$ & $21,66 \pm 5,03 \mathrm{~A}$ & $16,82 \pm 2,90 \mathrm{~A}$ \\
Metamielócito & $4,68 \pm 1,24 \mathrm{~B}$ & $7,38 \pm 2,24 \mathrm{~A}$ & $3,72 \pm 1,35 \mathrm{~B}$ \\
Basófilo & $0,25 \pm 0,21 \mathrm{~A}$ & $0,27 \pm 0,21 \mathrm{~A}$ & $0,30 \pm 0,43 \mathrm{~A}$ \\
Eosinófilo & $3,48 \pm 2,57 \mathrm{~A}$ & $4,66 \pm 2,70 \mathrm{~A}$ & $7,25 \pm 1,65 \mathrm{~A}$ \\
Neutrófilo & $24,60 \pm 3,90 \mathrm{~B}$ & $35,25 \pm 6,24 \mathrm{~A}$ & $39,93 \pm 4,79 \mathrm{~A}$ \\
Bastonete & $5,35 \pm 3,39 \mathrm{~A}$ & $5,05 \pm 6,11 \mathrm{~A}$ & $3,40 \pm 3,28 \mathrm{~A}$ \\
Rubroblasto & $1,83 \pm 0,99 \mathrm{~A}$ & $1,33 \pm 0,90 \mathrm{~A}$ & $1,11 \pm 0,90 \mathrm{~A}$ \\
Pró-rubrócito & $1,72 \pm 0,90 \mathrm{~A}$ & $2,05 \pm 1,85 \mathrm{~A}$ & $1,19 \pm 0,64 \mathrm{~A}$ \\
Rubrócito & $7,30 \pm 1,62 \mathrm{~A}$ & $2,66 \pm 2,06 \mathrm{~B}$ & $2,88 \pm 0,78 \mathrm{~B}$ \\
Metarrubrócito & $11,16 \pm 3,96 \mathrm{~A}$ & $3,28 \pm 1,39 \mathrm{~B}$ & $0,57 \pm 0,55 \mathrm{~B}$ \\
Plasmócito & $0,57 \pm 0,29 \mathrm{~A}$ & $0,27 \pm 0,38 \mathrm{~A}$ & $0,30 \pm 0,18 \mathrm{~A}$ \\
Linfócito & $22,97 \pm 7,33 \mathrm{~A}$ & $11,45 \pm 2,91 \mathrm{~B}$ & $14,25 \pm 2,27 \mathrm{~B}$ \\
Monócito & $0,47 \pm 0,59 \mathrm{~A}$ & $0,69 \pm 0,42 \mathrm{~A}$ & $1,07 \pm 1,31 \mathrm{~A}$ \\
Razão mieloide:eritroide & $2,48 \pm 0,56 \mathrm{~B}$ & $11,19 \pm 5,92 \mathrm{~A}$ & $13,91 \pm 1,83 \mathrm{~A}$ \\
\hline
\end{tabular}

Médias seguidas por letras distintas na linha indicam valores diferentes pelo teste $\mathrm{SNK}(\mathrm{P}<0,05)$.

Nos grupos hipotireoideo e hipertireoideo, houve redução significativa da população de rubrócitos, metarrubrócitos e linfócitos e aumento significativo de mielócitos e segmentados. No hipotireoidismo, constatou-se ainda aumento significativo da porcentagem de metamielócitos.
Os rubrócitos e os metarrubrócitos são células da linhagem eritroide que originam os eritrócitos. Assim, a redução da população dessas células na medula óssea das ratas hipo e hipertireoideas indica eritropoese inadequada com alteração da diferenciação das células da linhagem eritroide, o 
que explica a anemia observada em indivíduos hipotireoideos. No caso do hipertireoidismo, a ocorrência de anemia tem sido pouco relatada (Hambsch et al., 1989). Em ratas induzidas ao hipertireoidismo com a mesma dose de tiroxina e pelo mesmo período de tempo utilizados neste estudo, não foi observada anemia e nenhuma outra alteração do eritrograma (Gomes et al., 2004).

O aumento da população de mielócitos, nos grupos tratados, e ainda de metamielócitos, no hipotireoideo, refletiu na elevação da porcentagem de segmentados (neutrófilos). Entretanto, nem sempre as alterações evidenciadas no mielograma são acompanhadas por alterações dos constituintes celulares do sangue. Há pesquisas que demonstram alteração de um determinado tipo celular no mielograma e normalidade na célula que ele origina no sangue (Almeida et al., 2009). Dessa forma, é fundamental associar o mielograma com o hemograma para uma interpretação mais conclusiva. Apesar das alterações no mielograma, as ratas com hipertireoidismo não apresentaram nenhuma alteração no perfil hematológico, aspecto já observado por Carneiro et al. (2000). Já no hipotireoidismo, as alterações observadas no mielograma foram acompanhadas por alterações no sangue periférico, caracterizadas por anemia e por aumento do número de bastonetes, eosinófilos e monócitos, sem, no entanto, alterar o número total de leucócitos. Todavia, o número de neutrófilos e linfócitos no sangue periférico de ratas com hipotireoidismo não se alterou, diferentemente do que foi observado no mielograma.

Conclui-se que o hipotireoidismo causa hipoplasia da medula óssea e que tanto o hipo quanto o hipertireoidismo elevam a relação mieloide:eritroide por aumentar o número de células da linhagem mieloide e por reduzir as células da linhagem eritroide.

Palavras-chave: rata, mielograma, hipotiroidismo, hipertireoidismo

\begin{abstract}
The cells of the myeloid, lymphoid, and erythroid lineages of the bone marrow were quantified in rats with hypo and hyperthyroidism. Fifteen Wistar rats were divided into three groups: hypothyroid $(n=5)$, hyperthyroid $(n=5)$, and control $(n=5)$. Three months after the onset of the treatments, euthanasia was performed. Bone marrow was aspirated from femurs of each animal to perform smears that were stained with Quick Panoptic. The percentages of rubroblast, prorubrocyte, metarubrocyte, myeloblast, promyelocytes, metamyelocytes, myelocytes, segmented, eosinophils, basophils, lymphocytes, plasma cells and monocytes in were determined a total of 500 cells. The bone marrow of animals with hypothyroidism had hypoplasia. The myeloid:erythroid ratio was higher in animals with thyroid dysfunction. In hypo and hyperthyroidism, there was a significant reduction of the percentage of rubrocyte, metarubrocyte, and lymphocytes and increase of myelocytes and segmented cells. In hypothyroidism, there was a significant increase in the percentage of metamyelocytes. It is concluded that both hypo and hyperfunction of thyroid increase the myeloid:erythroid ratio by increasing the number of cells of the myeloid lineage and reducing the cells of the erythroid lineage.
\end{abstract}

Keywords: rat, myelogram, hypothyroidism, hyperthyroidism

\section{AGRADECIMENTOS}

Ao apoio financeiro do Conselho Nacional de Desenvolvimento Científico e Tecnológico (CNPq) e da Fundação de Amparo à Pesquisa do Estado de Minas Gerais (FAPEMIG).

\section{REFERÊNCIAS BIBLIOGRÁFICAS}

ALMEIDA, R.K.; VASCONCELOS, A.C.; CARNEIRO, R.A. et al. Alterações citológicas do sangue periférico e da medula óssea de cães com cinomose. Arq. Bras. Med. Vet. Zootec., v.61, p.1255-1260, 2009. 
BAUER, A.; MIKULITS, W.; LAGGER, G. et al. The thyroid hormone receptor functions as a ligand-operated developmental switch between proliferation and differentiation of erythroid progenitors. The EMBO J., v.17, p.4291-4303, 1998.

BRENT, G.A. The molecular basis of thyroid hormone action. N. Engl. J. Med., v.331, p.847$853,1994$.

CARNEIRO, R.A.; SERAKIDES, R.; SOUSA, C.M. et al. Perfil hematológico de ratas castradas e intactas induzidas experimentalmente ao hipertireoidismo. Arq. Bras. Med. Vet. Zootec., v.52, p.220-221, 2000.

DINNEN, R.D.; WHITE, S.R.; ELSAYED, S. et al. An endogenous signal triggering erythroid differentiation: identification as thyroid hormone. Cell Growth Differ., v.5, p.855-861, 1994.

FOSTER, M.P.; MONTECINO-RODRIGUEZ, E.; DORSHKIND, K. Proliferation of bone marrow pro-B cells is dependent on stimulation by the pituitary/thyroid axis. J. Immunol., v.163, p.5883-5890, 1999.

GOMES, M.G.; SERAKIDES, R.; NUNES, V.A. et al. Perfil hematológico de ratas adultas hipotireoideas castradas e não castradas. Arq. Bras. Endocrinol. Metab., v.48, p.294-298, 2004.
GOMES, M.G.; SILVA, C.M.; RIBEIRO, A.F.C. et al. Apoptose, proliferação e histomorfometria do baço de ratas adultas com hipofunção tireoidiana e ovariana. Arq. Bras. Endocrinol. Metab., v.52, p.1031-1038, 2008.

HAMBSCH, K.; HERRMANN, F.; FISCHER, $\mathrm{H}$. et al. Changes in the blood picture in hyperthyroidism. Z. Gesamte Inn. Med., v.44, p.300-306, 1989.

MONTECINO-RODRIGUEZ, E.; CLARK, R.; POWELL-BRAXTON, L. et al. Primary B cell development is impaired in mice with defects of the pituitary/thyroid axis. J. Immunol., v.159, p.2712-2719, 1997.

PATT, H.M. A Consideration of myeloiderythroid balance in man. Blood, v.12, p.777$787,1957$.

SCHROEDER, C.; GIBSON, L.; ZENKE, M. et al. Modulation of normal erythroid differentiation by endogenous thyroid hormone and retinoic acid receptors: a possible target for v-erbA oncogene action. Oncogene, v.7, p.217$227,1992$. 